concerned with their history. An immense amount of literary research has gone into it, and the author has ransacked the archives of America and Europe to bring together the information that he has skilfully welded into a fascinating account of the islands from their discovery to the present day. He has consulted the original log-books of the early explorers, official reports from naval officers of many nationalities engaged on surveying, and the letters and logs of whalers and tortoise-oil hunters. There can be few records of visits to the islands that he has not seen, and his illustrations range from reproductions of Cowley's drawings made in 1684 to photographs of many interesting nineteenth-century ships that worked there, and of living giant tortoises and of the devastation of broken carapaces left by the oil hunters. The paper concludes with a notice of all the scientific expeditions that have been at the Galápagos, sections on the giant tortoises and the preservation of the fauna, and a select bibliography. Slevin could have wished for no better monument.

L. Harrison Matthews

\title{
THE AUSTRALIAN DEFENCE STANDARDS LABORATORIES
}

$\mathrm{T}$ HE annual report of the Defence Standards Laboratories of the Department of Supply, Australian Defence Scientific Service, for the year ended June 301959 , the staff of which numbered 621 at the end of the year, compared with 637 at July 1, 1958, includes lists of senior and professional staff, papers published, and committees on which the Laboratories' staff have served*. The Laboratories, besides providing a scientific advisory service to those concerned with development, manufacture, inspecting, procurement, storage and use of defence material, have a recognized function of research, both in relation to their scientific advisory function and in advising and assisting the defence services on the development of new and improved materials, methods and equipment. The range of the Laboratories' activities may be illustrated by mentioning a few of the investigations on which some notes are given in the report.

In ehemistry these include studies of the pore structure and other physical characteristics of brown

* Commonwealth of Australia. Annual Report of the Defence Standards Laboratories for the year ended 30th June, 1959. Pp;
iv +75 . (Maribyrnong, Vic. : Defence Standards Laboratories, 1959.) coal and copra charcoals, the oxidation of phosphorus in the decomposition of cast iron by acid, determination of minute amounts of ammonia by Nessler's reagent and of small amounts of tin, and of the dyeing of textiles. In metallurgy the study of chromium and chromium base high-temperature alloys continued, as well as of the production of pure chromium, the processing, properties and structure of chromium and chromium alloys and also on titanium alloys. In physics, further experience was gained in the technique of electron spin resonance, the use of X-ray diffraction in studying the structural changes in the ageing of titanium-chromium alloys, and on the stabilization of a.c.-line voltages. A stable electric are was developed, and further work carried out on precise load measurement and the determination of garmma-ray source strengths. Miscellaneous work included improvements in electrophotography such as improved particulate photoconductor coatings of acceptance to charge on the surface, uniformity, sensitivity and spectral response, and the study of thin selenium films for xerography.

\section{HETEROGENEITY OF LECITHINS LABELLED WITH PHOSPHORUS-32}

\author{
By DR. F. D. COLLINS \\ Biochemistry Department, University of Melbourne
}

\begin{abstract}
NINCE the first use of phosphorus-32 in $1937^{1}$ for the study of phospholipid metabolism an immense amount of work has been done using this isotope; but in every case the results have been limited by the analytical methods used to separate the very complicated mixture of naturally occurring phospholipids. In the early work, for example, lecithin was isolated as the ethanol-soluble material, but this was far from pure. In more recent years the use of chromatography on alumina ${ }^{2,3}$ or silicic acid $^{2}$ has yielded lecithins which analysed correctly in that the molar ratio of phosphorus : choline : fatty acid plus fatty aldehyde was equal to $1: 1: 2$. In addition mild alkaline hydrolysis ${ }^{4,5}$ of lecithin has been shown to yield glycerylphosphoryl-choline, which could be isolated and purified by paper chromatography. The use of these procedures enabled the mean specific radioactivity to be determined but took no account of the possible effects of the different fatty acids and fatty aldehydes
\end{abstract}

that were present. Because of the absence of methods for fractionating the lecithins it has had to be assumed that any variation between lecithins was not large enough to invalidate comparisons of the specific radioactivities between the lecithins and other phospholipids. The following experiment shows that quite large variations in specific radioactivity can exist between different lecithins.

A rat $(310 \mathrm{gm}$.$) was injected intravenously with$ $0.8 \mathrm{mc}$. of labelled sodium dihydrogen phosphate in $0.1 M$ sodium chloride and $0.001 M$ sodium dihydrogen phosphate and killed after $90 \mathrm{~min}$. The liver lipids were extracted, dinitrophenylated and methylated as described by $m \theta^{6}$, and then divided at $-18^{\circ}$ into an acetone-soluble and an -insoluble fraction. The acetone-insoluble materials were free of dinitrophenyl-containing lipids, and countercurrent distribution (120 transfers) in carbon tetrachloride-chloroform-methylene chloride-methanol- 